Rev. Bras. Saúde Prod. Anim., Salvador, v.16, n.3, p.678-687 jul./set.., $2015 \quad$ http://www.rbspa.ufba.br

\title{
Desempenho produtivo e reprodutivo de fêmeas F1 Holandês x Nelogir ${ }^{1}$
}

\author{
Productive and reproductive performance in crossbred Holtein x Nelogir females
}

\author{
RAIDAN, Fernanda Santos Silva ${ }^{2}$; COSTA, Maria Dulcineia da ${ }^{2 *}$; RUAS, José \\ Reinaldo Mendes ${ }^{2,3}$; ROCHA JUNIOR,Vicente Ribeiro ${ }^{2}$; SILVA, Edilane Aparecida \\ $\mathrm{da}^{3}$; SANTIAGO, Ronaldo Lazzarini ${ }^{4}$; RIBEIRO, Antônia de Maria Filha ${ }^{2}$; RIBAS, \\ Wemerson Fábio Gomes ${ }^{2}$
}

\footnotetext{
${ }^{1}$ Parte do trabalho de dissertação de mestrado do primeiro autor, financiado pela FAPEMIG.

${ }^{2}$ Universidade Estadual de Montes Claros, Janaúba, Minas Gerais, Brasil.

${ }^{3}$ Empresa de Pesquisa Agropecuária de Minas Gerais, Secretaria de Agricultura e Abastecimento de Minas Gerais, Unidade Regional do Triângulo e Alto Paranaíba, Uberaba, Minas Gerias, Brasil.

${ }^{4}$ Fazenda Calciolândia, Arcos, Minas Gerais, Brasil.

*Endereço para correspondência: dulcineia.costa@unimontes.br
}

\section{RESUMO}

Objetivou-se avaliar as características produtivas e reprodutivas de fêmeas $1 / 2$ Holandês x $1 / 4$ Nelore, $1 / 4$ Gir (Nelogir). Avaliouse os efeitos de ordem e época de parto, do reprodutor da raça Gir e do reprodutor da raça Holandesa, avô materno e pais das matrizes 1/2 Holandês $\mathrm{x}$ Nelogir, respectivamente. A produção de leite total, com duração da lactação média de 288 dias, foi de $3.426,9 \mathrm{~kg}$ de leite. A ordem de parto influenciou a produção média diária que foi maior no segundo parto e a duração da lactação, superior nos animais de primeiro parto. O período de início das águas apresentou menor duração da lactação e produção por dia de intervalo de parto. A produção de leite total não variou de acordo com o reprodutor Gir, pai da Nelogir, e foi superior nas matrizes filhas de reprodutores Holandeses com PTA positivo para leite. Ao primeiro parto o pico de produção foi de $13,03 \mathrm{~kg}$ aos 45 dias de lactação, e a partir do segundo parto a produção foi decrescente desde o parto. Conclui-se que, em condições tropicais, as características produtivas e reprodutivas sustentam a iniciativa de produção de animais 1/2 Holandês x Nelogir a partir de matrizes compostas Nelogir e que a escolha do touro da raça Holandesa para produção de F1 HNG deve ser baseada no valor genético aditivo para produção de leite (PTA leite).

Palavras-chave: eficiência produtiva, mestiços leiteiros, PTA leite

\section{SUMMARY}

It was aimed to evaluate the productive and reproductive traits of $1 / 2$ Holstein $\times 1 / 4$ Nellore, $1 / 4$ Gir (Nelogir) females. They were evaluated the effects of order and season of calving, of Gir and Holstein sires grandfathers and fathers of the ${ }^{1 / 2}$ Holstein $x$ Nelogir matrices, respectively. Total milk production, with average lactation length of 288 days, was $3,426.9 \mathrm{~kg}$ of milk. The order of calving influenced the daily average production which was higher in the second calving and lactation length was superior in the first calving. The beginning of rain period (November to January) showed lower lactation length and production a day of calving interval. Total milk production did not vary according to Gir sire, Nelogir's father, and was higher in the matrices daughters of Holstein sires with positive PTA for milk. In the first calving the production peak was of $13.03 \mathrm{~kg}$ at 45 days of lactation, and from the second calving the production was descending one. In tropical conditions, productive and reproductive traits support the initiative of farm animals $1 / 2$ Holstein $\mathrm{x}$ Nelogir from matrices composed Nelogir and that the choice of Holstein bull to produce F1 HNG should be based on the genetic value milk production (milk PTA).

Keywords: crossbred dairy, productive efficiency, PTA milk 
Rev. Bras. Saúde Prod. Anim., Salvador, v.16, n.3, p.678-687 jul./set.., $2015 \quad$ http://www.rbspa.ufba.br

\section{INTRODUÇÃO}

Como alternativa para melhorar os índices produtivos do rebanho leiteiro nacional têm-se utilizado os cruzamentos envolvendo raças de origem indiana e europeia (VASCONCELLOS et al., 2003). Os animais F1, com maior grau de heterose, são mais eficientes em produção e reprodução no sistema de produção em pasto predominante no Brasil, quando comparados a animais puros ou com maior fração de genes da raça Holandesa (MADALENA et al., 1990; RUAS et al., 2010).

Preferencialmente esse cruzamento é realizado entre as raças zebuínas com maior potencial leiteiro, como a raça Gir (RUAS et al., 2007). No entanto, o número reduzido de matrizes da raça Gir tornou-se limitante para expansão da produção de fêmeas F1 (COSTA et al., 2010). Como alternativa de base materna, está sendo utilizado o composto zebuíno, comumente chamado Nelogir que é a primeira geração do cruzamento de reprodutores da raça Gir, reconhecidamente selecionada para produção de leite, com fềmeas da raça Nelore, maior efetivo nacional (SANTIAGO, 2004).

A partir dessa base materna, busca-se obter fêmeas F1 Holandês x Nelogir com bom potencial para produção leiteira associada à boa adaptação ao sistema de produção em pasto. Isso se deve pela ação aditiva dos genes advindos das raças Gir e Holandesa somada à resistência e à rusticidade da raça Nelore. Sendo assim, o numeroso rebanho Nelore com características como fertilidade aliada à superioridade genética da raça Gir para produção de leite pode favorecer a utilização dessa base materna como alternativa para formação de fêmeas F1.
Portanto, objetivou-se avaliar a viabilidade produtiva e reprodutiva de animais F1 Holandês $x$ Nelogir provenientes do cruzamento de touro Holandês com fêmeas 1/4 Nelore, 1/4 Gir.

\section{MATERIAL E MÉTODOS}

Foram analisados registros de produção e reprodução de 165 fêmeas $1 / 2$ Holandês x Nelogir da Fazenda Calciolândia, localizada no município de Arcos-MG, com 205 partos ocorridos no período de 2006 a 2010.

Para a formação da progênie $\mathrm{F} 1$ Nelogir, fêmeas da raça Nelore foram inseminadas com reprodutores da raça Gir em estação de monta com duração de quatro meses. As bezerras Nelogir oriundas desse cruzamento foram desmamadas aos sete meses e confinadas por um período de dois meses, de setembro a novembro (SANTIAGO, 2004). Durante o confinamento receberam cana-de-açúcar ou silagem de sorgo como volumosos e suplemento com $1,0 \mathrm{~kg}$ de caroço de algodão e $0,5 \mathrm{~kg}$ de concentrado à base de ureia para ganhos de peso não superiores a $500 \mathrm{gr} / \mathrm{cab} / \mathrm{dia}$. O confinamento teve como objetivo evitar perda de peso das bezerras durante o final da seca e início das chuvas, reduzir a carga animal sobre a pastagem no período de início de rebrota e condicionar as bezerras para futuros manejos (SANTIAGO, 2004). Após o confinamento, foram mantidas em pastos de capim Buffel e, ao atingirem idade entre 24 e 26 meses, foram inseminadas com touros da raça Holandesa.

As bezerras $1 / 2$ sangue Holandês $\mathrm{x}$ Nelogir permaneceram juntas em áreas restritas até a desmama e com manejo similar às F1 Nelogir, isto é, dieta suficiente para ganhos de peso de 500gramas/dia além de estímulo para 
Rev. Bras. Saúde Prod. Anim., Salvador, v.16, n.3, p.678-687 jul./set.., $2015 \quad$ http://www.rbspa.ufba.br ISSN 15199940

amansamento. Após o confinamento, foram transferidas para a Fazenda Calciolândia, mantidas em pasto e inseminadas com reprodutores Holandês com idade entre 24 e 26 meses. A partir da aferição da primeira lactação, são comercializadas de acordo com a produção leiteira. Os animais de menor produção são destinados ao mercado de receptoras de embriões enquanto aqueles de maior produção são destinadas aos produtores de leite.

As informações que constaram no arquivo zootécnico da fazenda foram identificação do animal, data do nascimento, data da cobertura, data do parto, data da secagem, data do controle leiteiro, produção total na lactação e a identificação do pai, da raça Holandesa, e do avô materno, da raça Gir. Foram avaliados 1.895 registros de produção de leite provenientes do controle leiteiro de 205 lactações efetuadas de 28 em 28 dias e com duração da lactação acima de 100 dias.

Os dados foram agrupados de acordo com quatro épocas de ocorrência dos partos e início da lactação. A época I consistiu de vacas que iniciaram a lactação nos primeiros três meses da seca (maio a julho); a época II com início da lactação nos últimos três meses da seca (agosto a outubro); a época III com vacas que iniciaram a lactação nos primeiros três meses das águas (novembro a janeiro); enquanto a época IV foram aquelas com início da lactação nos últimos três meses das águas (fevereiro a abril). Também foram agrupadas de acordo com a ordem de parto sendo a ordem I vacas de primeiro parto e a ordem II para vacas de segundo parto.

Foi avaliado o efeito da superioridade genética de touros das raças Holandesa e Gir sobre a produção de leite de suas filhas e netas, respectivamente. Para isto os touros da raça Gir, avós maternos das matrizes 1/2 Holandês x Nelogir, foram classificados de acordo com a PTA (Predicted Transmitting Ability) para leite, publicadas no sumário de touros de aptidão leiteira $(A B C Z, 2011) \mathrm{em}$ que a média da PTA para leite dos touros provados foi em torno de $200 \mathrm{~kg}$. Considerou-se como superior aqueles touros com PTA acima da média de $200 \mathrm{~kg}$; inferior foram os touros com PTA abaixo da média de $200 \mathrm{~kg}$ e não provados foram aqueles animais que não possuíam teste de progênie. Os touros da raça Holandesa, pais das matrizes 1/2 Holandês x Nelogir, foram classificados de acordo com a PTA para produção de leite em positivo e negativo de acordo com PTA publicadas no sumário de Nacional de touros da raça Holandesa (EMBRAPA GADO DE LEITE, 2011).

O modelo utilizado foi:

$\mathrm{Y}_{i j k l}=\mu+\mathrm{E}_{i}+\mathrm{OP}_{j}+\mathrm{REG}_{k}+\mathrm{REH}_{l}+$ $\mathrm{e}_{i j k l}$

em que:

$\mathrm{Y}_{i j k l}=$ produção total de leite; duração da lactação, produção média diária, intervalo de partos, período de serviço;

$\mu=$ constante;

$\mathrm{E}_{i}=$ efeito fixo da época de parição $i$ $(i=1,2,3,4)$

$\mathrm{OP}_{j}=$ efeito fixo da ordem de parição $(j=1,2)$;

$\mathrm{REG}_{k}=$ efeito do reprodutor Gir $k$ $(k=1,2,3)$

$\mathrm{REH}_{l}=$ efeito do reprodutor Holandês $l$ $(l=1,2)$.

Para as características produção total de leite (PT), duração da lactação (DL), produção média diária (PMD), intervalo de parto (IDP), período de serviço (PS) e idade ao parto (IP), as médias foram comparadas pelo teste StudentNewman-Keuls (SNK) a $5 \%$ de significância utilizando-se o procedimento PROC GLM do software SAS ( 2000). 
Rev. Bras. Saúde Prod. Anim., Salvador, v.16, n.3, p.678-687 jul./set.., $2015 \quad$ http://www.rbspa.ufba.br ISSN 15199940

Para determinar o comportamento da curva de lactação, em cada ordem de parto, utilizou-se análise de regressão da produção de leite em função do dia de lactação considerando o efeito linear e quadrático.

\section{RESULTADOS E DISCUSSÃO}

Não houve diferença significativa $(\mathrm{P}>0,05)$ na produção total de leite em $\mathrm{kg}(\mathrm{PT})$ do primeiro para o segundo parto (Tabela 1). As médias obtidas entre a primeira e segunda ordens de parto foi aproximadamente 2,5 vezes maior do que a média nacional de $1.492,31 \mathrm{~kg}$ de leite (IBGE, 2015) podendo portanto ser utilizadas para produção de leite. Ruas et al. (2010) encontraram médias de $3.025 \mathrm{~kg}$ de leite em 262 dias, para animais com a mesma composição genética deste estudo. Essa superioridade possivelmente se deve á composição genética destes animais visto que possuem $50 \%$ dos genes da raça Holandesa e $25 \%$ da raça Gir, selecionados para produção de leite. Além disto têm-se o manejo nutricional e o amansamento a que esses animais são submetidos o que contribui para melhor expressão do genótipo. Estes resultados diferem dos encontrados na literatura com animais F1 1/2 Holandês x Zebu (FACÓ et al., 2002; COSTA et al., 2010; GLÓRIA et al., 2010; GLORIA et al, 2012) em que as produções foram crescentes até o sexto parto. Como os animais, após a aferição da primeira lactação, são comercializados de acordo com o nível de produção, possivelmente a manutenção de animais de menor produção de leite no primeiro parto proporcionou produção similar no segundo parto. Isso é indicativo da eficiência do manejo adotado para adaptação do rebanho ao sistema de ordenha, comumente apontado como entrave da produção leiteira nos animais de primeira cria. No entanto, Ruas et al. (2010) não encontraram diferença significativa para ordens de parto devido ao maior peso ao parto e duração da primeira lactação.

A ordem de parto não influenciou as produções de leite aos 90 e 180 dias de lactação (Tabela1). Da produção total de leite $74,6 \%$ ocorreram até os 180 dias da lactação o que confirma a importância da produção inicial descrita por Ruas et al. (2010). Esses autores afirmaram que estratégias que visem ao aumento da produção de leite em vacas 1/2 Holandês x Zebu devem basear-se no aumento do pico de produção que normalmente ocorre logo no início da lactação.

McManus et al. (2008) encontraram, em vacas Holandesas e mestiças Holandês x Gir no Planalto Central, que tanto os valores da produção diária de leite quanto os da produção em 305 dias aumentaram conforme a ordem de parto e tiveram pico de produção na $6^{\text {a }}$ lactação. Segundo Souza et al. (2010) vacas de $3^{\text {a }}$ lactação (72 \pm 12 meses $)$ e $4^{\mathrm{a}} \quad$ lactação $(89 \pm 15$ meses $)$ apresentaram as maiores produções de leite, seguidas pelas vacas de $2^{\mathrm{a}}$ lactação (56 \pm 12 meses), enquanto as primíparas (36 \pm 7 meses) e as vacas de $5^{\mathrm{a}}$ lactação $(101 \pm 17$ meses $)$ foram menos produtivas. A maior produção observada nas vacas de $3^{\mathrm{a}}$ e $4^{\mathrm{a}}$ lactações estaria relacionada ao desenvolvimento da glândula mamária (REECE, 2007) e também com o crescimento corporal com maior capacidade de ingestão de alimentos, o que resultaria em maior produção de leite. Isso é consequência de um maior grau de maturidade fisiológica, como um todo, dos animais. Mais recentemente, em estudo com animais F1 Holandês x Zebu, Ruas et al. (2014) verificaram que os animais 
Rev. Bras. Saúde Prod. Anim., Salvador, v.16, n.3, p.678-687 jul./set.., $2015 \quad$ http://www.rbspa.ufba.br ISSN 15199940

Holandês x Gir e Holandês x Guzerá tiveram maior produção diária de leite a partir da sétima e quinta lactações, respectivamente enquanto nos animais F1 Holandês x Nelore a maior produção média ocorreu na sétima e oitava lactações. De acordo com os autores, as produções de animais F1 Holandês $\mathrm{x}$ Nelore, mesmo que menores que outros grupos, validariam estes grupos genéticos para produção de leite, uma vez que foram oriundos de rebanhos não selecionados para esta finalidade e ainda assim apresentaram produções médias diárias superiores a $10 \mathrm{~kg}$ diários a partir da quarta lactação, sendo compatíveis com a produção de leite a pasto. Este nível de produção poderia ser maior nas primeiras lactações caso estes animais recebessem cuidados diferenciados como aumento de peso e adaptação prévia ao sistema de ordenha (RUAS et al., 2014).

Tabela 1. Número de observações $(\mathrm{N})$, médias \pm desvio padrão dos desempenhos reprodutivo e produtivo de vacas F1 Holandês x Nelogir de acordo com a ordem de parto

\begin{tabular}{lcccc}
\hline \multirow{2}{*}{ Característica } & \multicolumn{4}{c}{ Ordem de parto* } \\
\cline { 2 - 5 } & $\mathrm{N}$ & Primeira & $\mathrm{N}$ & Segunda \\
\hline Produção Total de leite (Kg) & 165 & $3465,3^{\mathrm{a}} \pm 1087,4$ & 38 & $3334,1^{\mathrm{a}} \pm 849,6$ \\
Duração da Lactação (dias) & 165 & $288,9^{\mathrm{a}} \pm 61,2$ & 38 & $256,9^{\mathrm{b}} \pm 62,1$ \\
Produção Média Diária (kg) & 165 & $11,9^{\mathrm{b}} \pm 2,1$ & 38 & $13,1^{\mathrm{a}} \pm 2,3$ \\
Produção Leite 90 dias (Kg) & 148 & $1292,2^{\mathrm{a}} \pm 436,3$ & 31 & $1299,2^{\mathrm{a}} \pm 336,8$ \\
Produção Leite 180 dias (Kg) & 148 & $1228,3^{\mathrm{a}} \pm 385,6$ & 31 & $1153,5^{\mathrm{a}} \pm 339,7$ \\
Período de Serviço (dias) & 126 & $108,9^{\mathrm{a}} \pm 80,1$ & 29 & $107,2^{\mathrm{a}} \pm 74,8$ \\
Intervalo de Partos (dias) & 126 & $394,6^{\mathrm{a}} \pm 80,0$ & 29 & $392,2^{\mathrm{a}} \pm 74,8$ \\
PROD/IDP (kg) & 111 & $8,98^{\mathrm{a}} \pm 2,4$ & 23 & $8,71^{\mathrm{a}} \pm 2,2$ \\
\hline
\end{tabular}

*Médias com letras iguais na mesma linha não diferem estatisticamente $(\mathrm{P}>0,05)$ pelo teste SNK.

Não houve diferença estatística $(\mathrm{P}>0,05)$ nos período de serviço (PS) e intervalo de partos (IDP) entre $o$ primeiro e segundo partos. Os valores de PS e IDP são próximos aos ideais, ou seja, 80 e 365 dias, respectivamente, para obtenção de um bezerro por vaca por ano. Possivelmente essa eficiência reprodutiva se deva à heterose máxima desse cruzamento associada às condições favoráveis de manejo da fazenda.

A época do parto teve efeito significativo $(\mathrm{P}<0,05)$ sobre a duração da lactação com menor duração para lactações iniciadas no período de novembro a janeiro, isto é, os três primeiros meses das águas (Tabela 2).
Nesse período, provavelmente, esses animais não foram suplementados por já se encontrarem no final da lactação associado à melhor qualidade das pastagens.

Durante os meses da seca (maio a outubro), os animais receberam suplementação com volumoso, e nos três últimos meses das águas, o pasto já havia recuperado sua capacidade de produção de massa verde que podem ter favorecido a produção de leite por um período maior.

A PT, a PMD, o IDP, o PS, o IP não foram influenciados pela época do parto o que sugere uniformidade no manejo, adaptação dos animais às instalações e regularidade no regime alimentar. 
Rev. Bras. Saúde Prod. Anim., Salvador, v.16, n.3, p.678-687 jul./set.., $2015 \quad$ http://www.rbspa.ufba.br ISSN 15199940

A PROD/IDP foi menor no início do período das águas e maior nos três últimos meses da seca. Apesar de o PS não ser diferente entre as épocas do ano, foi capaz de interferir na variável em questão, visto que esta é obtida em função daquele com a produção total.

No primeiro parto, o pico de produção (PP) ocorreu aos 45 dias com produção de 13,03kg, estimados a partir da equação de regressão (Figura 1).

Tabela 2. Número de observações (n), médias \pm desvio padrão dos desempenhos reprodutivo e produtivo de vacas F1 Holandês x Nelogir de acordo com a época de parto

\begin{tabular}{|c|c|c|c|c|c|c|c|c|}
\hline \multicolumn{9}{|c|}{ Época de parto** } \\
\hline Características* & $\mathrm{n}$ & Nov-jan & $\mathrm{n}$ & Fev-abr & $\mathrm{n}$ & Mai-jul & $\mathrm{n}$ & Ago-out \\
\hline PT (Kg) & 40 & $3181,4^{\mathrm{a}} \pm 890,7$ & 52 & $3353,6^{\mathrm{a}} \pm 1023,9$ & 57 & $3457,9^{\mathrm{a}} \pm 984,0$ & 54 & $3698,5^{\mathrm{a}} \pm 1189,8$ \\
\hline DL (dias) & 40 & $260,9^{\mathrm{b}} \pm 63,6$ & 52 & $278,7^{\mathrm{a}} \pm 61,5$ & 57 & $292,3^{\mathrm{a}} \pm 57,7$ & 54 & $293,2^{\mathrm{a}} \pm 63,7$ \\
\hline PMD (kg) & 40 & $12,3^{\mathrm{a}} \pm 2,4$ & 52 & $12,0^{\mathrm{a}} \pm 2,6$ & 57 & $11,8^{\mathrm{a}} \pm 2,5$ & 54 & $12,4^{\mathrm{a}} \pm 2,3$ \\
\hline IDP (dias) & 24 & $398,1^{\mathrm{a}} \pm 62,8$ & 46 & $385,9^{\mathrm{a}} \pm 87,0$ & 47 & $414,4^{\mathrm{a}} \pm 91,4$ & 38 & $376,5^{\mathrm{a}} \pm 50,9$ \\
\hline PS (dias) & 24 & $113,1^{\mathrm{a}} \pm 62,8$ & 46 & $100,9^{\mathrm{a}} \pm 87,0$ & 47 & $127,7^{\mathrm{a}} \pm 91,8$ & 38 & $91,5^{\mathrm{a}} \pm 50,9$ \\
\hline IP(meses) & 40 & $36,6^{\mathrm{a}} \pm 6,7$ & 52 & $35,9^{\mathrm{a}} \pm 6,4$ & 57 & $35,5^{\mathrm{a}} \pm 5,1$ & 54 & $36,2^{\mathrm{a}} \pm 3,9$ \\
\hline $\begin{array}{l}\mathrm{PROD} / \mathrm{IDP} \\
\text { (kg/dia) }\end{array}$ & 22 & $8,3^{\mathrm{b}} \pm 2,4$ & 38 & $9,1^{\mathrm{ab}} \pm 2,3$ & 37 & $8,3^{\mathrm{ab}} \pm 2,4$ & 37 & $9,5^{\mathrm{a}} \pm 2,3$ \\
\hline
\end{tabular}

*PT = produção de leite total; $\mathrm{DL}=$ duração da lactação; $\mathrm{PMD}=$ produção média diária; IDP = intervalo de partos; PS = período de serviço; IP = idade ao parto; PROD/IDP = produção de leite por dia de intervalo de parto; $\mathrm{n}=$ número de observações.

**Médias com letras iguais na mesma linha não diferem estatisticamente $(\mathrm{P}>0,05)$ pelo teste SNK..

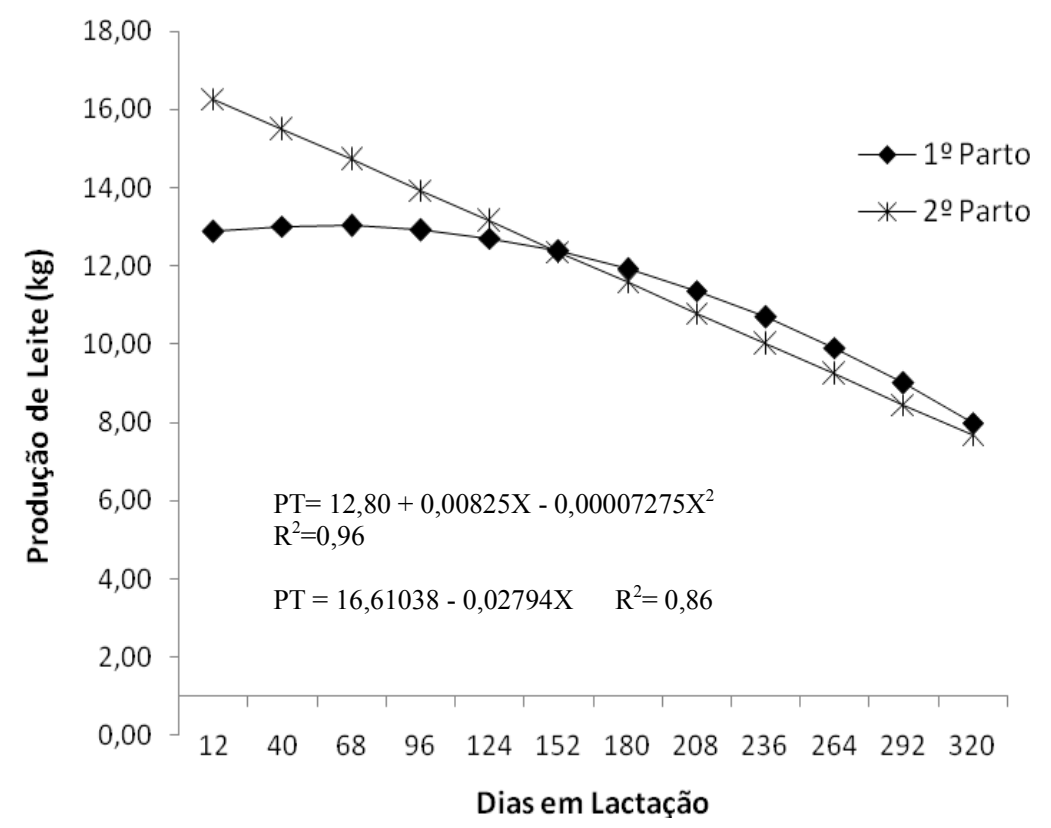

Figura 1. Comportamento da produção de leite de vacas $1 / 2$ Holandês x Nelogir em função dos dias em lactação de acordo com a ordem de parto 
Rev. Bras. Saúde Prod. Anim., Salvador, v.16, n.3, p.678-687 jul./set.., $2015 \quad$ http://www.rbspa.ufba.br ISSN 15199940

Ruas et al. (2010) descreveram médias semelhantes para PP de 12,08; 10,17 e $12,10 \mathrm{~kg}$ de leite aos 67,$3 ; 71,1$ e 40,9 dias de lactação para fêmeas mestiças de base materna Gir, Guzerá e Zebu, respectivamente. Maiores tempos do início da lactação ao pico são desejáveis, pois possibilitaram maior tempo para desafiar nutricionalmente o animal, de modo que possa expressar todo potencial genético e maximizar a produção total de leite (GLÓRIA et al., 2010, GLÓRIA et al., 2012). O pico de produção para animais de primeira cria é mais tardio que nas demais ordens de parto visto que esses animais estão em processo de adaptação ao sistema de ordenha.

O comportamento da produção de leite de vacas 1/2 Holandês x Nelogir no segundo parto não apresentou pico (Figura 1) e foi decrescente desde a ocorrência do parto, semelhante ao descrito por Oliveira et al. (2007) em mestiças 1/2 Holandês $x$ Gir. Esse comportamento é considerado atípico. Glória et al. (2010) explicaram que isso ocorre quando o pico de lactação acontece em momento anterior ao primeiro controle, e, como as pesagens de leite nesse trabalho foram avaliadas, em média, de 28 em 28 dias, o pico de produção pode não ter sido identificado de forma eficaz. Na literatura, a curva de lactação padrão é aquela que apresenta três fases distintas; primeira, a fase ascendente, que vai do parto até o pico (produção inicial); segunda, a produção máxima (pico de lactação), e terceira a fase descendente, a persistência (JAKOBSEN et al., 2002; FERREIRA \& BEARZOTI, 2003).

$O$ efeito da raça do touro utilizado como pai ou avô materno comportou de forma diferenciada (Tabela 3). Os touros da raça Gir de maior PTA para leite não proporcionaram aumento na produção de leite total de suas netas, ou seja, a superioridade genética não foi traduzida em maior produção.

Tabela 3. Número de animais (n), média \pm desvio padrão da produção total de leite de acordo com a raça e a classificação do pai da raça Holandesa e do avô materno da raça Gir

\begin{tabular}{|c|c|c|c|c|c|}
\hline $\begin{array}{l}\text { Raça do } \\
\text { touro }\end{array}$ & Positivo (n) & Negativo (n) & Superior (n) & Inferior (n) & $\begin{array}{l}\text { Não provado } \\
\text { (n) }\end{array}$ \\
\hline Holandês* & $\begin{array}{c}3530,5^{\mathrm{a}} \pm 1001,7 \\
(131)\end{array}$ & $\begin{array}{c}3150,6^{b} \pm 905,5 \\
(48)\end{array}$ & -- & -- & -- \\
\hline Gir* & 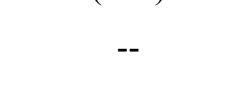 & 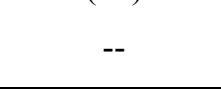 & $\begin{array}{c}3487,1^{\mathrm{a}} \pm 1059,9 \\
(154)\end{array}$ & $\begin{array}{c}3293,4^{\mathrm{a}} \pm 1057,7 \\
(28)\end{array}$ & $\begin{array}{c}3296,6^{\mathrm{a}} \pm 913,1 \\
(21)\end{array}$ \\
\hline
\end{tabular}

*Médias com letras iguais na mesma linha não diferem estatisticamente $(\mathrm{P}>0,05)$ pelo teste $\mathrm{SNK}$.

No entanto, os reprodutores da raça Holandesa com PTA negativa para leite proporcionaram menor PT das suas filhas que os reprodutores com PTA positiva. Dessa forma, é importante ser criterioso na definição do touro a ser utilizado como pai na produção de F1 HZ para que não ocorra decréscimo na produção leiteira. Esses resultados foram semelhantes aos encontrados por Glória et al. (2006) para 1/2 Holandês X Zebu, filhas de pais com PTA negativo nos EEUU. Esses autores explicaram que a falta de avaliações genéticas adequadas e o tamanho da amostra (30 vacas filhas de touros "leiteiros" e 50 "não leiteiros") influenciaram os resultados. Vaccaro et al. (2003) 
Rev. Bras. Saúde Prod. Anim., Salvador, v.16, n.3, p.678-687 jul./set.., $2015 \quad$ http://www.rbspa.ufba.br ISSN 15199940

estudaram o efeito do uso de touros Holandês de valor genético variando de superior a médio, provados nos EEUU, no desempenho de suas filhas F1, na Venezuela. Os autores observaram que as filhas dos touros com valor genético superior produziram, em média, $41 \%$ a mais de leite do que aquelas filhas dos touros com valor genético médio. Desse modo, o uso de touro Holandês de comprovado valor genético justifica-se como alternativa para cruzamento com vacas zebuínas para produção de fêmeas F1 (VACCARO et al. 2003).

Considerando o avô materno da raça Gir, não se observou diferença significativa para produção de leite total dentro das classificações superior, inferior e sem prova, independentemente do PTA do touro Holandês (Tabela 4).

Tabela 4. Produção total de leite $(\mathrm{kg})$ das filhas de touro Holandês com PTA Positivo ou negativo de acordo com a classificação do avô materno Gir

\begin{tabular}{lcccc}
\hline \multirow{2}{*}{ Avô materno Gir } & \multicolumn{4}{c}{ Touro Holandês* } \\
\cline { 2 - 5 } & $\mathrm{n}$ & Positivo & $\mathrm{n}$ & Negativo \\
\hline Superior & 99 & $3538,0^{\mathrm{a}}$ & 35 & $3247,9^{\mathrm{a}}$ \\
Inferior & 17 & $3620,9^{\mathrm{a}}$ & 6 & $3046,8^{\mathrm{a}}$ \\
Não Provado & 15 & $3377,9^{\mathrm{a}}$ & 7 & $2753,4^{\mathrm{a}}$ \\
\hline
\end{tabular}

*Médias com letras iguais na mesma linha não diferem estatisticamente $(\mathrm{P}>0,05)$ pelo teste $\mathrm{SNK}$.

Para os três grupos avaliados (superior, inferior e sem prova), não foi identificada a superioridade genética dos reprodutores da raça Holandesa com PTA positiva para leite, provavelmente devido ao pequeno número de observações.

As características produtivas e reprodutivas sustentam a iniciativa de produção de animais 1/2 Holandês a partir de matrizes compostas Nelogir. A escolha do touro da raça Holandesa para produção de F1 HNG deve ser baseada no valor genético aditivo para produção de leite (PTA leite). A utilização de reprodutores da raça Gir de comprovada superioridade genética na produção de leite não traduziu em aumento de leite em suas netas.

\section{AGRADECIMENTOS}

Á Coordenação de Aperfeiçoamento de Pessoal de Nivel Superior (CAPES), á Fundação de Amparo à Pesquisa do Estado de Minas Gerais
(FAPEMIG) pelo apoio financeiro e á Fazenda Colonial pela cessão dos dados.

\section{REFERÊNCIAS}

ASSOCIAÇÃO BRASILEIRA DE CRIADORES DE ZEBU - ABCZ.

Sumário de touros de aptidão leiteiraGir e Gir Mocha, 2011. 9.ed.

Araçatuba: PMGZ/UNESP. 2011.

COSTA, M. D. da; RUAS, J. R. M.; ROCHA JUNIOR, V. R.; RAIDAN, F.S.S; FERREIRA, J.J; SILVA, E.A. da. Importância do rebanho F1 Holandês x Zebu para pecuária de leite. Informe Agropecuário, v.31, n.258, p.40-50, 2010.

EMBRAPA GADO DE LEITE. Sumário Nacional de Touros da Raça Holandesa - 2011. Juiz de Fora:, 2011.40p. (Documentos, 149). 
Rev. Bras. Saúde Prod. Anim., Salvador, v.16, n.3, p.678-687 jul./set.., $2015 \quad$ http://www.rbspa.ufba.br ISSN 15199940

FACÓ, O.; LÔBO, R.N.B.; MARTINS

FILHO, R.; MOURA, A.A.A. Análise do desempenho produtivo de diversos grupos genéticos Holandês x Gir no Brasil.

Revista Brasileira de Zootecnia, v.31, n.5, p.1944-1952, 2002.

FERREIRA, E.B.; BEARZOTI, E. Comparação de métodos no ajustamento de curvas de lactação de bovinos por meio de simulação. Ciência e Agrotecnologia, v.24, n.5, p.865-872, 2003.

GLÓRIA, J.R. da.; BERGMANN, J.A.G.; REIS, R.B. ; COELHO, M.S.; SILVA, M.A. Efeito da composição genética e de fatores de meio sobre a produção de leite, a duração da lactação e a produção de leite por dia de intervalo de partos de vacas mestiças Holandês-Gir.

Arquivo Brasileiro de Medicina Veterinaria e Zootecnia, v.58, n.6, p.1139-1148, 2006.

GLÓRIA, J.R. da.; BERGMANN, J.A.G.; QUIRINO, C.R.; RUAS, J.R.M; MATOS, C.R.A. de; PEREIRA, J.C.C. Curvas de lactação de quatro grupos genéticos de mestiças Holandês- Zebu.

Revista Brasileira de Zootecnia, v.39, n.10, p.2160-2165, 2010.

GLÓRIA, J. R. da ; BERGMANN, J. A. G.; QUIRINO, CÉLIA RAQUEL; RUAS, J. R. M. ; PEREIRA, J. C. C.; REIS, R. B.; COELHO, S. G.; SILVA, M. A. Environmental and genetic effects on the lactation curves of four genetic groups of crossbred Holstein-Zebu cows. Revista Brasileira de Zootecnia (Online), v.41, p.2309-2315, 2012.

INSTITUTO BRASILEIRO DE GEOGRAFIA E ESTATÍSTICA IBGE. Pesquisa Pecuária Municipal. 2015. Disponível em: < http://www.sidra.ibge.gov.br>. Acesso em: 2 set. 2015.
JAKOBSEN, J.H.; MADSEN, P.; GENSEN, J.; PEDERSEN, J.; CHRISTENSEN, L.G.; SORENSEN, D.A. Genetic parameters for milk production and persistence for Danish Holstein estimated in random regression models using REML. Journal of Dairy Science, v.85, n.6, p.1607-1616, 2002.

MADALENA, F.E.; TEODORO, R.L.; LEMOS, A.M.; MONTEIRO, J.B.N.; BARBOSA, R.T. Evaluation of strategies for crossbreeding of dairy catle in Brazil. Journal of Dairy Science, v.73, p.1887-1901. 1990.

McMANUS, C.; TEIXEIRA, R. A.; DIAS, L. T.; LOUVANDINI, H.; OLIVEIRA, E.M. B. Características produtivas e reprodutivas de vacas Holandesas e mestiças Holandês $\times$ Gir no Planalto Central. Revista Brasileira de Zootecnia, v.37, n.5, p.819-823, 2008.

OLIVEIRA, H. T.V.; REIS, R.B.; GLÓRIA, J.R. QUIRINO, C.R.; PEREIRA, J.C.C. Curvas de lactação de vacas F1 Holandês-Gir ajustadas pela função gama incompleta. Arquivo Brasileiro de Medicina Veterinaria e Zootecnia, v.59, n.1, p.233-238, 2007.

REECE, W.O. Dukes: fisiologia dos animais domésticos. 12.ed. Rio de Janeiro: Guanabara Koogan S.A., 2007. 946p.

RUAS, J.R.M.; CARVALHO, B.C.; SILVA FILHO, J.M.; SILVA, M.A.; PALHARES, M.S.; BRANDÃO, F.Z. Efeito da base materna da estação de parição sobre variáveis produtivas de fêmeas primíparas Holandês x Zebu. Arquivo Brasileiro de Medicina Veterinária e Zootecnia, v.59, n.1, p.218-224, 2007. 
RUAS, J.R.M; MENESES, A.C.; CARVALHO, B.C.; QUEIROZ, D.S.; SILVA, E.A. da; FERREIRA, J.J. Sistema de produção de leite com vacas F1 Holandês x Zebu. Informe Agropecuário, v.31, p.63-71, 2010.

RUAS, J.R.M.; SILVA, E.A.;QUEIROZ, D. S.; PEREIRA, M. E. G.;SOARES JÚNIOR, J. A. G.; SANTOS, M. D.; ROCHA JÚNIOR, V. R.; COSTA, M.D. Características produtivas da lactação de quatro grupos genéticos F1 Holandês x Zebu. Revista Brasileira de Ciências Veterinárias, v.21, n.1, p.33-37, 2014.

\section{STATISTICAL ANALYSIS SYSTEM} - SAS. User's guide: statistics.

Version 8.0. Cary: NC., SAS Institute, 2000 .

SANTIAGO, R.L. Projeto Nelogir. Cruzamento Nelore x Gir como matriz para F1. Resultados parciais In: ENCONTRO DE PRODUTORES DE F1, 5., 2004, Belo Horizonte. Anais... Belo Horizonte, 2004. p.151-162.

SOUZA, R.; SANTOS, G. T.;

VALLOTO, A. A.; SANTOS, A. L.; GASPARINO, E.; SILVA, D. C.; SANTOS, W. B.R. Produção e qualidade do leite de vacas da raça Holandesa em função da estação do ano e ordem de parto. Revista Brasileira de Saúde e Produção Animal [online], v.11, n.2, p. 484-495, 2010.

VACCARO, L.; LOPEZ, J.; VACCARO, R.; VERDE, O.; MEJÍAS, H.; DORTA, D.; PÉREZ, A. Relation between Holstein bull's proofs for milk in USA and the milk yield, age at first calving, calving interval and survival to third calving of tehir F1 zebu progeny in Venezuela. Journal Animal

Breeding and Genetic, v.120, n.3, p.171-180, 2003.
VASCONCELLOS, B. de F. e; PÁDUA, J.T.; MUÑOZ, M.F.C.; TONHATI, H. Efeitos genéticos e ambientais sobre a produção de leite, o intervalo de partos e a duração da lactação em um rebanho leiteiro com animais mestiços, no Brasil. Revista Universidade Rural: Série Ciências da Vida, v.23, n. 1, p.39-45, 2003.

Data de recebimento: $29 / 06 / 2014$ Data de aprovação: 03/09/2015 